UNIVERSIDADE DE SÃO PAULO

FACULDADE DE ECONOMIA, ADMINISTRAÇÃO E CONTABILIDADE DEPARTAMENTO DE ADMINISTRAÇÃO PROGRAMA DE PÓS-GRADUAÇÃO EM ADMINISTRAÇÃO

UMA CONTRIBUIÇÃO AO DESENVOLVIMENTO DA EDUCAÇÃO EM FINANÇAS PESSOAIS NO BRASIL

André Taue Saito

Orientador: Prof. Dr. José Roberto Ferreira Savoia 
Prof $^{\mathrm{a}}$. Dr ${ }^{\mathrm{a}}$. Suely Vilela

Reitora da Universidade de São Paulo

Prof. Dr. Carlos Roberto Azzoni

Diretor da Faculdade de Economia, Administração e Contabilidade

Prof. Dr. Isak Kruglianskas

Chefe do Departamento de Administração

Prof. Dr. Lindolfo Galvão de Albuquerque

Coordenador do Programa de Pós-Graduação em Administração 


\title{
UMA CONTRIBUIÇÃO AO DESENVOLVIMENTO DA EDUCAÇÃO EM FINANÇAS PESSOAIS NO BRASIL
}

\author{
Dissertação apresentada ao \\ Departamento de Administração da \\ Faculdade de Economia, Administração \\ e Contabilidade da Universidade de São \\ Paulo como requisito para a obtenção do \\ título de Mestre em Administração.
}

Orientador: Prof. Dr. José Roberto Ferreira Savoia 
FICHA CATALOGRÁFICA

Elaborada pela Seção de Processamento Técnico do SBD/FEA/USP

Saito, André Taue

Uma contribuição ao desenvolvimento da educação em finanças pessoais no Brasil / André Taue Saito. -- São Paulo, 2007.

$152 \mathrm{p}$.

Dissertação (Mestrado) - Universidade de São Paulo, 2007

Bibliografia.

1. Finanças 2. Educação I. Universidade de São Paulo. Faculdade de Economia, Administração e Contabilidade II. Título.

CDD - 332 